\title{
A REVOLUÇÃO EM ETAPAS E A BOLCHEVIZAÇÃO PRECOCE DOS COMUNISTAS NO BRASIL (anos vinte)
}

\section{Pedro Roberto Ferreira}

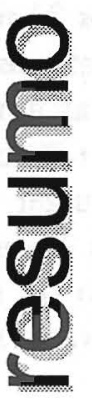

\section{Prof. do Departamento de Ciências Sociais da UEL}

O texto é uma pequena parte de pesquisas sobre a esquerda brasileira num período compreendido entre 19201946. Trata de observações sobre o início das influências do Komintern no PCB, e de como essas impediram um desenvolvimento dentro do marxismo que pudesse fornecer à organização nacional, uma teoria da revolução que viesse condicionar o partido numa perspectiva histórica-bibliografia:

Palavras-chave: Internacional Comunista, Bolchevismo, Revolução Socialista, Imperialismo, Partido Comunista

$\mathrm{S}$ abidamente, é o VI Congresso da Internacional Comunista, realizado em 1928, que amarra laços mais estreitos com o movimento comunista latino-americano e, por conseqüência, como Partido Comunista do Brasil. Esse estreitamento traz consigo um controle maior da I.C. sobre as suas seções latinoamericanas, afirmam os estudiosos do movimento comunista ${ }^{1}$. Simultâneo a esse controle, a América Latina por se situar na órbita da revolução mundial, passa a requerer maior apoio técnico, ideológico e financeiro, da Internacional Comunista.

Não são raros os textos que se debruçam sobre as influências da Internacional Comunista sobre os Partidos, sinonimizando estalinização de bolchevização, confundindo e dificultando a análise de um momento bastante especial do movimento revolucionário internacional.

A história da bolchevização pode ser remontada aos inícios da estruturação da organização revolucionária internacional: o Partido

\footnotetext{
${ }^{1}$ Paulo Sérgio Pinheiro Estratégias da Ilusão pg 147, Cia das Letras, SP, 1991. ver também, José Aricó Marxe a América Latina pg 31, Ed. Paz e Terra, RJ, 1982.
}

da Revolução Mundial tem como gênese a vitória dos bolcheviques na Rússia, em outubro de 1917, e faz se edificar ${ }^{2}$ no mesmo local, sendo quase inevitáveis as influências da organização liderada por Lênin e Trotsky na I.C, criada em 1919. Entretanto, uma coisa será a forte influência bolchevique; outra, a hegemonia do partido na própria organização. Mais interessante perceber é que quase toda a liderança revolucionária bolchevique estava bem consciente das possíveis mazelas desse processo político na I.C. Lênin mesmo transita pelos dois pólos, aqui fazendo a crítica da absolutização de algumas táticas bolcheviques, acolá generalizando certos instrumentos históricos de luta a todos os países, incluídos com sucesso na revolução de 17. Diante de certas vicissitudes da revolução na Alemanha, era capaz de proferir abstrações sobre a organização revolucionária, em outros momentos revelava todos os seus receios a respeito da bolchevização. "Os estrangeiros não necessitam

\footnotetext{
${ }^{2}$ Essa questão foi discutida pelos revolucionários europeus veja-se a posição de Rosa Luxemburg, contrária à localização da I.C. em solo russo.
} 
disso. Necessitam já de qualquer coisa de mais elevado: isto refere-se, em primeiro lugar, a que compreendam também aquilo que escrevemos acerca da estrutura orgânica dos partidos comunistas, e que os camaradas estrangeiros assinaram sem ler nem compreender. Esta deve tornar-se a sua primeira tarefa. É preciso levar esta resolução à prática. Mas isso não pode fazer-se da noite para o dia, é absolutamente impossível. A resolução é demasiado russa: reflete a experiência russa, por isso os estrangeiros não a compreendem e não podem satisfazer-se com pendurá-la num canto como um ícone e adorá-la. Assim não se pode conseguir nada. Eles devem assimilar parte da experiência russa" 3 .

Quando, sob a reflexão da importância dos "soviets", a Internacional Comunista lança o seu Manifesto março de 1919de abertura dos trabalhos, parecia querer equilibrar, mediar, as influências de todas as organizações revolucionárias que se apresetaram sentaram da sua fundação. Sendo o "soviets" uma organização pertinente é claro dependendo do momento histórico a todo o movimento social do proletariado, o ponto de partida da organização internacional nivelava democraticamente todas as possíveis diferenças ${ }^{4}$, na revolução mundial. Nem a sua repugnância ao Socialismo tributário da II Internacional maculavathe o sentido aglutinador. A idéia que circulava entre os revolucionários europeus durante a guerra, de criar uma organização sucessora da $2^{a}$.Internacional Socialista $^{5}$ composta somente pelas esquerdas, concretizar-se.

Com o advento do chamado "Comunismo de Guerra", que agravou ainda mais a já crítica situação econômica e social da noviça República Socialista, levou internamente a uma espécie de condensação daquilo que significasse Socialismo à dramática atitude tudo pela defesa da revolução ${ }^{6}$. O 2 Congresso da Internacional Comunista realizado

\footnotetext{
${ }^{3}$ Lenine "Cinco anos da Revolução Russa e Perspectivas da Revolução Mundial" 4 Congresso da I.C. (Pravda 258,15111922) in Obras Escolhidas pg 628, Ed. AlfaÔmega,SP1980.

4 "Os soviets não eram uma criação original russa" v.Rudolf Rocker Bolchevismo y Anarquismo pg 40, Ed. Reconstruir, Buenos Aires, 1959.

${ }^{5}$ E. H. Carr La Revolución Bolchevique ( 19171923) pg 583, vl 3, Alianza Ed, Madrid, 1974. ver também, Isaac Deutscher Trotsky "El Profeta Armado" pg 412, Ed. Era, México, 1966. ${ }^{6}$ Pierre Broue El Partido Bolchevique pgs 167, 168, 169, Ed. Ayuso, Madrid, 1973.
}

em 1920 e que concluiu pelos 21 pontos, expressou muito bem esse contexto histórico. "A situação política mundial colocou agora na ordem do dia a ditadura do proletariado, e todos os acontecimentos da política mundial se concentram inevitavelmente em torno de um ponto central, a saber: a lutada burguesia mundial contra a República Soviética da Rússia, que agrupa necessariamente em torno de si, por um lado, os movimentos soviéticos dos operários avançados de todos os países e, por outro lado, todos os movimentos de libertação nacional das colônias e das nacionalidades oprimidas, que se convencem pela amarga experiência de que não há salvação para elas senão na vitória do Poder Soviético sobre o imperialismo mundial ${ }^{7}$."

Mergulhando nas determinações dos 21 pontos parece que a Internacional Comunista entendeu que a proteção do Socialismo russo contra as ameaças da burguesia internacional se faria com o cerco e um ataque à Social Democracia. A julgar pelas referências literais, nada menos do que 12 artigos são destinados à crítica do reformismo da social democracia, e o restante se compondo praticamente ao redor do 12 (décimo segundo) ponto.

A preocupação da Internacional Comunista estava no possível fortalecimento da Social Democracia européia que, ao lado do auxílio dos Estados Unidos, poderiam apressar a recuperação do Capitalismo europeu sob a hegemonia do Imperialismo inglês. A hipótese de uma luta revolucionária na América do Norte unificaria o movimento operário de todo o Continente e impediria a presença dos Estados Unidos na Europa $^{8}$, e no seu efeito endógeno, quebraria a hegemonia do Imperialismo ianque.

A entrada dos países de economia retardatária no processo de industrialização capitalista na revolução mundial recebe uma teorização condensada no 8 (oitavo) ponto. "Na questão das colônias e das nacionalidades oprimidas, os partidos cuja burguesia possui colônias ou oprime nações, devem observar uma linha de conduta particularmente clara e nítida. Todo o partido pertencente à Terceira Internacional tem por dever desvendar despiedosamente as proezas de "seus" imperialistas. Nas colônias, sustentar, não só

\footnotetext{
${ }^{7} 7$ Lenin Obras Escogidas pg 121, vl XI, Ed. Progreso, Moscu, 1977.

${ }^{8}$ v. "Sur la révolution en Amérique" pgs 3307,3308,in

"L'Internacionale Communiste", Rev. C.Ex.I.C, 15, janvier, 1921 .
} 
palavras, mas de fato todo movimento de emancipação, exigir a expulsão das colônias dos imperialistas da metrópole, alimentar no coração dos trabalhadores do país sentimentos verdadeiramente fraternais em relação à população laboriosa das colônia se das nacionalidades oprimidas, e manter, entre tropas da metrópole, uma agitação contínua contra toda opressão dos povos coloniais." É a chamada concepção de revolução para os países coloniais e semicoloniais que, nos anos vinte, terá como modelo a revolução na China. Todavia, até o V Congresso da Internacional Comunista, a questão colonial é marginal nas suas principais preocupações. Veja se, por exemplo, a fixação da América Latina em relação aos Estados Unidos.

As teses do PCB, em "Agrarismo e Industrialismo", com a projeção de uma revolução democrática posta em movimento através da pequena burguesia, reproduzem, com fidelidade, as avaliações do Komintern para o problema colonial.

Para os comunistas, as etapas da revolução brasileira hospeda uma interpretação do industrialismo essencialmente compreendido no seu fator exógeno, ou seja, nas relações criadas pelo domínio do Capitalismo imperialista. Exatamente por isso, o industrialismo obstaculiza a marcação das relações feudais geradas pelo latifúndio sem a necessidade de uma revolução agrária. Embora, justiça seja feita, o 2 Congresso da I.C, pedisse uma transformação no campo para os países coloniais e semicoloniais, sem qualquer indenização, o PCB a omite ${ }^{10}$. Do 2 Congresso dos Comunistas brasileiros não sairá nenhum programa agrário para a revolução.

$\mathrm{O}$ industrialismo que se desenvolve e fortalece a burguesia liberal interna, inelutável do agrarismo, pulveriza as bases de sustentação do Imperialismo inglês e, necessariamente, fortalece $o$ ianque, porque a sua razão de ser indica nesse momento a impossibilidade da revolução socialista.

Essa vitalidade do Imperialismo ianque, nas bases materiais internas do Brasil, revela a irresistível expansão de uma economia que sai vencedora no pós Primeira Grande Guerra Mundial,

\footnotetext{
${ }^{9}$ Rudolf Schesinger "Formulación de la línea generalcomunista y su aplicación hasta el comienzo de la Revolución China" in La Internacional Comunista y el Problema Colonial pg.43, Pasado y Presente, Siglo XXI, México, 1977.

${ }^{10}$ Lenin, op.cit, tomo XI, pgs $127,128,129$ e segs.
}

demarcando os limites da primeira etapa da revolução no Brasil, segundo o Partido Comunista.

A existência da economia norte-americana em território brasileiro poderia contrariar a tese da Internacional Comunista para todo o Continente; os ianques, porém, se sentiriam ameaçados com a presença da vanguarda comunista no processo revolucionário da pequena burguesia. Ameaças que se inscrevem na disposição e no projeto de luta dos comunistas para a 2 (segunda) etapa da revolução. Assim foi possível, no final do 2 (segundo) Congresso, a seguinte chamada: "O II Congresso do PCB, ao encerrar seus trabalhos, saúda em geral a todos os partidos irmãos de todo o mundo e em especial aos partidos de toda a América, com os quais o PCB deve colaborar mais de perto na luta contra o Imperialismo ianque; aos partidos vizinhos sul-americanos, o II Congresso envia a mais fraternal palavra de solidariedade e saudação, indicando ao PCB a necessidade de estabelecer com os mesmos, para o futuro, relações mais estreitas e efetivas do que até aqui, em vista de uma atividade comum..."11

$\mathrm{Na}$ segunda etapa da revolução em que o partido comunista mais a pequena burguesia derrotariam a burguesia liberal, também se destruiriam os alicerces do domínio do Imperialismo norte-americano. Nos escombros desse domínio, o proletariado, agora aparecendo como sujeito, já indica a via socialista da revolução, porque a sua concentração nas fábricas, afirma Brandão ${ }^{12}$, adquiriu um conteúdo político, modificando o significado do Industrialismo. Nesse momento, a crítica ao conjunto do Capitalismo imperialista anglo/americano se impõe, visto que, na crítica à burguesia liberal brasileira, se acha toda a recusa ao Capital. Finalmente, coloca o Brasil no eixo da revolução mundial na medida em que passa a contar com uma vanguarda revolucionária da classe operária e dos trabalhadores na construção do seu projeto.

Para os comunistas, a 2 (segunda) etapa da revolução parecia se adiantar na realidade brasileira, porquanto a referênciada revolução chinesa $^{13}$ vai se dimensionar, mais concreta mente, com a anunciada preparação do Bloco Operário em

\footnotetext{
${ }^{11}$ Edgar Carone O P.C.B. pg 42, vl 1, Difel, SP, 1982.

${ }^{12}$ Octávio Brandão Agrarismo e Industrialismo pg36, edição (microficha) A.E.L. Unicamp, Campinas, SP.

${ }^{13}$ essa referência aparece na obra de O.Brandão jámencionada neste texto.
} 
junho de 1925, no jornal do partido "A Classe Operária".

Os encaminhamentos de passagem da 2 (segunda) etapa à 3 (terceira) etapa da revolução não foram mencionados no texto de Octávio Brandão, muito menos discutidos no interior do2(segundo) Congresso do PCB.

Presume-se que o industrialismo, na compreensão dos comunistas, levaria a um desenvolvimento tão grande da classe operária, que a pequena burguesia seria naturalmente tragada por esse processo. No primeiro momento, a indústria do Capitalismo imperialista solapa suas bases reais, ditadas na pequena propriedade, no pequeno negócio, etc, para, no segundo, lhe impor uma proletarização nas condições de vida. Dessa maneira, quando a pequena burguesia apela em nome de uma política nacionalista, o faz em defesa própria, procurando se proteger do Imperialismo.

$\mathrm{O}$ atrelamento dessa pequena burguesia em frangalhos ao proletariado entenda-se a direção do PCB era uma consequiência lógica, porque somente ele poderia enfrentar com eficácia o Imperialismo. Não procede, portanto, a crítica tardia de Astrojildo Pereira a Octávio Brandão pelas suas análises do Imperialismo: "Partindo de tais concepções, que resultavam de uma aplicação mecânica e arbitrária do método dialético na análise da situação brasileira, os movimentos que desembocaram no 5 de julho de1922 e no 5 de julho de 1924 são simplesmente enquadrados no esquema "agrarismoindustrialismo", e dentro desse enquadramento isolados do contexto vivo da situação política. Ao considerar " fator imperialista", as teses dizem que ele devia "também" ser levado em conta na caracterização da política nacional. Era um fator como outro qualquer, talvez, até secundário." 14

A inserção do Imperialismo na realidade brasileira, feita por $\mathrm{O}$. Brandão e os comunistas, foi condicionada às teses do Komintern, sem dúvida, através de uma leitura apressada que redundou em uma grande generalização. Mas generalizar uma realidade histórica com muitas especificidades também foi privilégio da Internacional Comunista ${ }^{15}$

\footnotetext{
${ }^{14}$ Astrojildo Pereira Notícia do II Congresso inEnsaios Históricos e Políticos pg. 92, Ed. AlfaÔmega, SP, 1979.

${ }^{15}$ Aldo Agosti acha que a Internacional Comunistafreou a revolução mundial quando pretendeu mediar as diferen ças próprias do Capitalismo enquanto produção desigual. ver "O mundo da III Internacional: os estados maiores" in E.Hobs
}

quando, depois de 1920, procurou absolutizar o projeto bolchevique de revolução. Em julho de1923, em resolução do Executivo Ampliado da I.C. ${ }^{16}$, surgia, mais uma vez, a proposta de aliança entre a classe operária e o campesinato como questão capital para o sucesso da revolução proletária internacional.

Em "Agrarismo e Industrialismo" e nas discussões do2(segundo) Congresso do Partido Comunista, as indicações do proletariado, dos trabalhadores rurais e camponeses, foram feitas no mais absoluto nominalismo, sem a menor conexão com a realidade concreta.

Assim, nem mesmo uma falsa aparência no tratamento privilegiado do proletariado poder-se-ia creditar ao PCB como uma influência em demasia de Lênin das "As tarefas dos Social Democratas Russos"17, posto que operários e camponeses desaparecem na figura do sujeito indeterminado. Embora se falasse em latifúndio a propriedade rural não fora analisada, menos ainda a divisão do trabalho, segundo a cooperação/competição impostas pelo domínio do capital no interior das fábricas. Não se indagou sobre as origens do campesinato diante do predomínio esmagador da grande propriedade no campo.

Pode-se dizer que uma prematura bolchevização colheu o PCB, devido a sua fragilidade teórica e de certas imposições da I.C. que, voluntária ou involuntariamente, fechou-lhe as portas para aquisição de um marxismo "original".

Esse processo provocou um impacto deletério no Comunismo Brasileiro e, de forma diferenciada, em muitos partidos comunistas latino-americanos. O Partido Comunista da Argentina foi apontado ${ }^{18}$ como o mais influenciado nesse período, havendo ultrapassado essa fase ao comportar uma lealdade à

bawm História do Marxismo pg 109, vl 16, Ed.Paz e Terra, RJ, 1985.

${ }^{16}$ Resolutions de L'Executif Elárgi (1923), in La

Correspondance Internationale pg 2, 54, IC.

${ }^{17}$ Lênin afirma que nas condições dadas o proletariado sintetiza toda a exploração do homem. ver "Cahiers Philosophiques"pg 24, Ed.Sociales, Paris, 1973. Mas a revolução pressupõea análise do proletariado historicamente determinado porque é dessa compreensão que se o terá como direção de todo o processo. Deste modo, o partido deve privilegiar a apreensão da situação do proletariado sem perder de vista, no entanto, as condições do campesinato. ver Lenin Las Tarefas de los Social Demócratas Rusos pg 378, Tomo I, op.cit, 1979.

18 Jorge Abelardo Ramos História del Stalinismo enla Argentina pg 55 e segs, Ed. D. Dulce, Argentina, 1969. 
cartilha da fração liderada por Stálin, invocando críticas duríssimas a Trotsky e seus seguidores.

No Brasil, o Partido Comunista com o seu jornal "A Classe Operária", permanecia aberto às saudações de todas as grandes lideranças da Revolução de 1917, e o livro de Octávio Brandão, publicado em 1926, abrigava Lênin e Trotsky como expressões máximas do operariado mundial ${ }^{19}$.

Se antes a bolchevização da Internacional Comunista era uma preocupação, entre 1924/1925 passa a ser abertamente defendida sob as luzes do 5 (quinto) Congresso e a tese do "Socialismo em um só país". Com o célebre discurso de Zinoviev "As Perspectivas Internacionais e a Bolchevização" no Executivo Ampliado da I.C, em março de $1925^{20}$, serão esclarecidas as principais coordenadas para que os partidos comunistas alcancem o mais breve possível essa política desnorteadora dos princípios marxistas.

Os objetivos e os métodos da bolchevização, defende Zinoviev, são a Organização e uma política justas. Uma boa linha política (linha justa) somente se consegue com uma boa organização, e essa está, como sempre esteve, com os bolcheviques. Sacramenta-se, desta forma, a organização do partido sob os princípios do centralismo democrático, independentemente, de quaisquer processos históricos da revolução.

\section{REFERÊNCIAS BIBLIOGRÁFICAS}

"La Correspondance Internationale" 19191943 I.C.

(microficha A.E.L, Unicamp, Campinas).

"L'Internationale Communiste" Révue Comité

Executif19191943 I.C. (microficha A.E.L, Unicamp,

Campinas).

Lenine Cahiers Philosophiques Ed.Sociales, Paris, 1973.

Lenin Obras Escogidas Ed.Progreso, Moscu, 1977.

Lenine Obras Escolhidas Ed.AlfaÔmega, SP,1980.

Paulo Sérgio Pinheiro Estratégias da Ilusão Ed.Ciadas

Letras, SP, 1991.

José Aricó Marx e a AméricaLatina Ed.Paz e Terra,RJ, 1982.

Rudolf Rocker Bolchevismo y Anarquismo

Ed.Reconstruir, Buenos Aires, 1959.

E.H.Carr La Revolución Bolchevique Alianza Ed,Madrid, 1974.
Isaac Deutscher Trotsky "El Profeta Armado" Ed.Era,México, 1966.

Pierre Broue El Partido Bolchevique Ed. Ayuso, Madrid, 1973.

Jorge Abelardo Ramos História del Stalinismo en la Argentina Ed. D.Dulce, Argentina, 1969.

Rudolf Schesinger La Internacional Comunista y el Problema Colonial Ed. Siglo XXI, México, 1977.

Edgar Carone O P.C.B. Difel, SP, 1982. 15 Octávio Brandão Agrarismo e Industrialismo 1926, (microficha A.E.L, Unicamp, Campinas).

Astrojildo Pereira Ensaios Históricos e Políticos Ed.

AlfaÔmega, SP, 1979.

E.Hobsbawm História do Marxismo Ed.Paz e Terra,RJ, 1985.

${ }^{19}$ Octávio Brandão, op. cit, pg 16.

${ }^{20} \mathrm{La}$ Correspondance Internacionale, órgão da I.C,5 année, 42, 2441925, pg 325. ver também Pierre Broue, op.cit, pg 270. 